Esta revista forma parte del acervo de la Biblioteca Jurídica Virtual del Instituto de Investigaciones Jurídicas de la UNAM

\title{
Práctica convencional del Estado mexicano
}

\section{ACUERDO SOBRE LA FACILITACIÓN DEL COMERCIO ${ }^{1}$}

El 26 de julio de 2016, el Estado mexicano presentó su instrumento de ratificación de este acuerdo el cual tiene como finalidad agilizar los procedimientos aduaneros y facilitar el movimiento, el despacho de aduana y la puesta en circulación de las mercancías. De acuerdo con la $\mathrm{OMC}$, entrará en vigor cuando dos tercios de los miembros presenten su instrumento de aceptación, actualmente el número de ratificaciones asciende a $89 .{ }^{2}$

\section{SECRETARÍA DE RELACIONES EXTERIORES ${ }^{3}$}

1. México, "Amigo de la Corte" en demanda para preservar derecho de hijos de indocumentados nacidos en Texas

El 24 de agosto de 2015, el gobierno presentó un escrito de "amigo de la Corte" (Amicus curiae) ante la Corte Federal del Distrito Occidental de

1 Elaborado por Susana Marisol Hernández Alonso. Alumna en la Facultad de Ciencias Políticas y Sociales de la UNAM.

2 El Acuerdo sobre la Facilitación del Comercio, puede consultarse en: https: / / www.wto. org/spanish/tratop_s/tradfa_s/tradfa_s.htm (última consulta del 29 de agosto de 2016)

3 Información obtenida de la Prensa de la Secretaria de Relaciones Exteriores, disponible en: https: / / www.gob.mx/sre julio 2015-septiembre 2016. Elaborado porYazareth Alejandra Sánchez Rivera. Asistente de investigación en el Instituto de Investigaciones Jurídicas. 
Esta revista forma parte del acervo de la Biblioteca Jurídica Virtual del Instituto de Investigaciones Jurídicas de la UNAM www.juridicas.unam.mx

Texas, en apoyo a la demanda presentada por diversas organizaciones de la sociedad civil, entre los cuales se encuentran nacionales mexicanos, guatemaltecos y hondureños, para preservar el derecho de hijos de padres indocumentados nacidos en ese estado a recibir un certificado de nacimiento como ciudadanos estadounidenses.

El objetivo de este escrito es preservar el derecho a la identidad de los hijos de mexicanos nacidos en Texas y garantizar que puedan disfrutar plenamente de los derechos garantizados por las leyes locales.

2. México presenta escrito de "Amigo de la Corte" sobre el caso del menor Hernández Güereca

El 3 de septiembre 2015, el gobierno mexicano presentó un escrito de "Amigo de la Corte" (Amicus curiae) ante la Suprema Corte de Estados Unidos, buscando una revisión de la decisión de una corte de apelaciones de negarles el derecho a una indemnización por la muerte de un menor, ocurrida en 2010, a causa de un disparo de arma de fuego hacia un menor en las inmediaciones de la línea fronteriza en Ciudad Juárez, Chihuahua, por un agente de la Patrulla Fronteriza, quien se encontraba en territorio estadounidense.

En el escrito, México reitera su deber de velar por el respeto de los derechos de sus nacionales, especialmente en aquellos casos en que se han violado sus garantías fundamentales. En ese sentido, se destaca también la obligación contemplada por instrumentos internacionales de derechos humanos aceptados por Estados Unidos, de garantizar el derecho a un recurso efectivo y a una reparación debida cuando tales garantías no son respetadas por autoridades nacionales.

3. México anuncia que enviará observadores a la misión de la ONU en Colombia

10 mayo de 2016, México informó hoy que contribuirá con el envío de efectivos a la misión que la ONU enviará a Colombia para monitorear y verificar el alto el fuego cuando se haya firmado el acuerdo de paz para ese país. 
Esta revista forma parte del acervo de la Biblioteca Jurídica Virtual del Instituto de Investigaciones Jurídicas de la UNAM www.juridicas.unam.mx

4. México presenta escrito de "Amigo de la Corte" en Corte Federal de Apelaciones de Estados Unidos en el caso de José Antonio Elena Rodríguez

El 12 de mayo, el gobierno mexicano presentó un escrito de Amigo de la Corte (Amicus curiae) ante la Corte Federal de Apelaciones del Noveno Circuito, con sede en San Francisco, California, en el caso de un menor, muerto en 2012, por disparos de un agente de la Patrulla Fronteriza desde territorio estadounidense, cuando la víctima se encontraba en Nogales Sonora, México con esto, se busca promover el derecho de la madre del connacional a demandar, ante tribunales estadounidenses, una indemnización por la trágica muerte de su hijo.

En su escrito, México reitera que, derivado de sus obligaciones internacionales en materia de derechos humanos, Estados Unidos ha reconocido que ninguna persona puede ser privada de la vida arbitrariamente y que, en caso de violación a los derechos de una persona, ésta podrá interponer un "recurso efectivo" ante los tribunales.

5. México: Altos Comisionados de la ONU acogen con beneplácito la reforma constitucional sobre asilo

El 22 de abril de 2016, las Oficinas en México del Alto Comisionado para los Refugiados (ACNUR) y para los Derechos Humanos acogieron con beneplácito la aprobación por el Senado de la República de la reforma constitucional en materia de asilo, dicho texto reconoce el derecho de toda persona a buscar y recibir asilo, lo cual resulta relevante para la protección internacional de las personas refugiadas en México. 
Esta revista forma parte del acervo de la Biblioteca Jurídica Virtual del Instituto de Investigaciones Jurídicas de la UNAM www.juridicas.unam. $m x$

DOI: http://dx.doi.org/10.22201/iij.24487872e.2017.17.11053

III. RESOLUCIONES EMITIDAS POR LOS ÓRGANOS DE CONTROL DE TRATADOS INTERNACIONALES EN MATERIA DE DERECHOS HUMANOS ${ }^{4}$

\section{Relatoría Especial para la Libertad de Expresión ${ }^{5}$}

La Relatoría Especial, de la Comisión Interamericana de Derechos Humanos, ha llamado la atención por los asesinatos de periodistas ocurridos en lo que va del año, siete hasta el momento ${ }^{6}$. Conforme al principio 9o. de la Declaración de Principios sobre la Libertad de Expresión, misma que sirve de base a la actividad de la Relatoría Especial para la protección y promoción del artículo 13 de la Convención Americana de Derechos Humanos, el Estado mexicano está obligado a prevenir e implementar las medidas de protección necesarias frente a esta clase de delitos, y en el caso, resolverlos adecuadamente.

\section{Grupo Interdisciplinario de Expertos Independientes (GIEI)}

El 6 de septiembre de 2015 se presentó el informe y primeras conclusiones por parte del Grupo Interdisciplinario de Expertos Independientes, relacionadas a la desaparición de los 43 estudiantes de la Escuela Normal Rural Isidro Burgos en Ayotzinapa, Guerrero; suceso acontecido los días 26 y 27 de septiembre de 2014. En el informe se resaltaron "las irregularidades, inconsistencias y ausencias en la investigación de los hechos por parte de las autoridades estatales”, lo que puso en duda la versión dada a conocer por la Procuraduría General de la República. Como consecuencia del trabajo y las recomendaciones emitidas por el GIEI, el Estado mexicano abrió nuevas líneas de investigación referente a los sucesos.

4 Elaborado por Rodrigo Emilio Castro Bizarretea. Asistente de investigación en el Instituto de Investigaciones Jurídicas.

5 Seguimiento de los comunicados de la Organización de Estados Americanos, disponible en: http: / / www.oas.org/es/cidh/prensa/comunicados.asp.

6 Septiembre de 2015 a agosto de 2016. 
Esta revista forma parte del acervo de la Biblioteca Jurídica Virtual del Instituto de Investigaciones Jurídicas de la UNAM

\section{Informe Situación de Derechos Humanos en México}

El 2 de marzo de 2016 la Comisión Interamericana de Derechos Humanos publicó su informe sobre la protección de los derechos humanos en México. Producto de la visita In Loco realizada del 28 de septiembre al 2 de octubre de 2015, la CIDH observó la situación de los derechos humanos en el país, sus actividades colocaron mayor énfasis en desapariciones forzadas, ejecuciones extrajudiciales y tortura, inseguridad ciudadana, la falta de acceso a la justicia, impunidad, la situación de periodistas, defensores y defensoras de derechos humanos, y otros grupos especialmente afectados por el contexto de violencia en el país.

La Comisión Interamericana constató en su informe:

...la grave crisis de derechos humanos que se vive, caracterizada por una situación extrema de inseguridad y violencia; graves violaciones, en especial desapariciones forzadas, ejecuciones extrajudiciales y tortura; niveles altos de impunidad y una atención inadecuada e insuficiente a las víctimas y familiares. Los más afectados por la violencia y las violaciones a los derechos fundamentales son personas en situación de pobreza, personas migrantes, solicitantes de asilo, refugiados y desplazados internos, mujeres, niños, niñas y adolescentes, defensoras y defensores de derechos humanos, periodistas, pueblos indígenas, personas lesbianas, gay, bisexuales y trans (LGBTI), entre otros. Destacó que la violencia contra familiares de víctimas, defensores de derechos humanos y periodistas es ejercida con el objetivo de silenciar las denuncias, y perpetuar la impunidad para las graves violaciones a los derechos humanos. ${ }^{8}$

\section{Visitas In Loco}

El comisionado James Cavallaro realizó una visita de trabajo a México los días 22, 23 y 24 de septiembre de 2015, en el marco de las actividades relativas a los mecanismos de soluciones amistosas y seguimiento de peticiones y casos. La visita tuvo como objetivo monitorear la situación de derechos

7 Idem.

8 Idem.

9 Idem. 
Esta revista forma parte del acervo de la Biblioteca Jurídica Virtual del Instituto de Investigaciones Jurídicas de la UNAM www.juridicas.unam.mx

humanos de las personas privadas de libertad en el país, además, realizar actividades relativas a los mecanismos de soluciones amistosas y seguimiento de peticiones y casos.

Durante la visita, se dieron las suscripciones de diversos acuerdos de cumplimiento, de soluciones amistosas, entre otros. La CIDH valoró los esfuerzos del Estado mexicano en la construcción de una política de búsqueda de solución amistosa y cumplimiento de los asuntos pendientes ante el sistema de peticiones y casos individuales.

En matería de visitas a los reclusorios, la Relatoría constató que en reclusorios federales y estatales en México, se presentan patrones comunes y estructurales, tales como hacinamiento, corrupción, indebida atención médica, falta de privacidad, ausencia de oportunidades reales para la reinserción social, maltrato por parte del personal penitenciario a cargo de la custodia de las personas privadas de libertad, e imposibilidad de éstas para presentar quejas ante un órgano independiente que cumpla con los estándares de independencia e imparcialidad reconocidos.

Asimismo, la Comisión observó que se presenta en gran medida un uso excesivo de la prisión preventiva y la inaplicación de medidas sustantivas. Durante la visita a los centros de readaptación, se recibieron testimonios de personas cuyos casos habrían excedido ampliamente el límite constitucional para la aplicación de la prisión preventiva.

\section{Celebración de tratados ${ }^{10}$}

El 15 de junio de 2016, en el marco del $46^{\circ}$ Periodo Ordinario de Sesiones de la Asamblea General de la OEA, se aprobó la Declaración Americana sobre los Derechos de los Pueblos Indígenas. Este instrumento reconoce la libre determinación de los pueblos originarios, la protección a sus territorios ancestrales, su derecho a consulta y consentimiento libre e informado, así como la protección de la igualdad de género al interior de las comunidades, entre otros derechos y garantías. La presente declaración se suma a otros instrumentos como son la Declaración de Naciones Unidas sobre los Derechos de Pueblos Indígenas, el Convenio 169 de la Organización Internacional del Trabajo, entre otros.

10 Idem. 
Esta revista forma parte del acervo de la Biblioteca Jurídica Virtual del Instituto de Investigaciones Jurídicas de la UNAM

6. Cumplimiento de las recomendaciones en materia de reparación y medidas de no repetición ${ }^{11}$

La CIDH, en su INFORME 80/15-CASO 12689, reconoció y constató el cumplimiento pleno por parte del Estado mexicano de las recomendaciones emitidas por dicho órgano, en el caso de discriminación cometidas en perjuicio de dos ciudadanos que fueron dados de baja del Ejército Mexicano por ser portadores del virus de inmunodeficiencia humana (VIH), afectando su vida privada e integridad personal, así como vulnerando su derecho a las garantías y a protección judicial.

El 18 de diciembre de 2015, en cumplimiento de las recomendaciones hechas por la CIDH ante la situación de los migrantes en el país, el Estado mexicano creó la Unidad de Investigación de Delitos para Personas Migrantes y el Mecanismo de Apoyo Exterior Mexicano de Búsqueda e Investigación, ambos vinculados a las actividades de la Procuraduría General de la República (PGR).

\section{ACTIVIDAD DE MÉXICO}

EN LA ORGANIZACIÓN DE LAS NACIONES UNIDAS (ONU) ${ }^{12}$

El 25 de septiembre de 2015, el Estado mexicano adoptó la Agenda 2030 para el Desarrollo Sostenible, la cual cuenta con 17 objetivos de desarrollo sostenible (ODS) y 169 metas que tienen como fin erradicar la pobreza, combatir la desigualdad y la injusticia, y afrontar el cambio climático.

El 30 de septiembre de 2015, México y Francia presentaron una iniciativa de veto en el marco del 70o. periodo de sesiones de la Asamblea General de las Naciones Unidas cuyo propósito es restringir el uso de veto de los miembros permanentes del Consejo de Seguridad (China, Estados Unidos, Francia, Reino Unido y Rusia) en los casos de crímenes en masa.

11 Idem.

12 Información obtenida del Centro de Noticias, de la Organización de las Naciones Unidas http: / / www.un.org/spanish / News / Julio 2015- Septimbre 2016. Elaborado por Susana Marisol Hernández Alonso y Yazareth Alejandra Sánchez Rivera. 
Esta revista forma parte del acervo de la Biblioteca Jurídica Virtual del Instituto de Investigaciones Jurídicas de la UNAM www.juridicas.unam.mx

El 8 de noviembre de 2015, la Asamblea General de las Naciones Unidas aprobó cuatro resoluciones presentadas por México en materia de desarme nuclear. Las iniciativas son: Impacto Humanitario de las Armas Nucleares, Promesa Humanitaria, Dimensión Ética para alcanzar un Mundo Libre de Armas Nucleares y Avance en las negociaciones multilaterales en materia de desarme nuclear.

El 25 de noviembre de 2015, el Estado mexicano y la Organización de las Naciones Unidas para la Igualdad y el Empoderamiento de las Mujeres firmaron un convenio de colaboración para la creación de un Protocolo para la Atención Consular a Víctimas de Violencia basada en Género.

El 29 de noviembre de 2015, la Organización de las Naciones Unidas adoptó cuatro resoluciones presentadas por México en materia de los derechos de las personas con discapacidad, los derechos humanos y las libertades en la lucha contra el terrorismo, la cooperación internacional contra el problema mundial de las drogas y, la protección a migrantes.

El 12 de diciembre de 2015, México adoptó el Acuerdo de París sobre Cambio Climático. De conformidad a su artículo 2o., tiene como objetivo "reforzar la respuesta mundial a la amenaza del cambio climático, en el contexto del desarrollo sostenible y de los esfuerzos por erradicar la pobreza”. El Acuerdo entrará en vigor a partir del 2020.

El 13 de diciembre de 2015, México envió ocho elementos militares a las Operaciones de Mantenimiento de Paz (OMP), sumando un total de doce miembros en todo el año. Su participación será en la Misión de las Naciones Unidas para la Estabilización de Haití (MINUSTAH), la Misión de las Naciones Unidas para el Referéndum del Sáhara Occidental (MINURSO) y la Fuerza Provisional de las Naciones Unidas para Líbano (UNIFIL).

El 29 julio de 2016, las oficinas en México de ONU Mujeres, el Alto Comisionado para los Derechos Humanos y el Fondo de Población (UNFPA) rechazaron la reforma a la Constitución Política de Veracruz que garantiza el derecho a la vida desde el momento de la concepción.

1o. de agosto de 2016, La Oficina en México del Alto Comisionado de la ONU para los Derechos Humanos acogió con beneplácito la reciente emisión de la Ley Nacional de Ejecución Penal. La nueva legislación destaca la recuperación de los más altos estándares internacionales sobre las condiciones de detención, el reconocimiento de las personas privadas de la libertad como titulares de derechos, el enfoque diferenciado en su tratamiento y la creación de procedimientos administrativos y judiciales para que se respeten esos derechos. 


\section{PODER LEGISLATIVO ${ }^{13}$}

El 15 de agosto de 2016, en el Diario Oficial de la Federación se publicó el decreto por el que se reforma el párrafo segundo del artículo 11 de la Constitución Política de los Estados Unidos Mexicanos, mismo que establece:

"Toda persona tiene derecho a buscar y recibir asilo. El reconocimiento de la condición de refugiado y el otorgamiento de asilo político, se realizarán de conformidad con los tratados internacionales. La ley regulará sus procedencias y excepciones".

Ahora bien, de conformidad con el artículo 22, párrafo 7 de la Convención Americana de Derechos Humanos: "Toda persona tiene el derecho de buscar y recibir asilo en territorio extranjero en caso de persecución por delitos políticos o comunes conexos con los políticos y de acuerdo con la legislación de cada Estado y los convenios internacionales".

Por lo anterior, cabe resaltar que se aporta sustento constitucional que respalda la Convención de la que México es parte puesto que estos preceptos ahora se hallan en concordancia atendiendo a la protección del derecho de asilo y la protección de refugiados, sin olvidar el respeto a los derechos humanos consagrado en el Constitución Política de los Estados Unidos Mexicano.

13 Véase el decreto de reforma en: http://www.dof.gob.mx/nota_detalle.php?codigo $=5447$ 903\&fecha $=15 / 08 / 2016$ (fecha de consulta: 16 de agosto de 2016). Elaborado por Wendy Sánchez Reyes. 